\title{
Microstructure Evolution and Simulation in 22MnB5 Steel during Hot Stamping
}

\author{
Kuanhui Hu, Shizheng Zhou, Rongdong Han, Jun Gao, Yi Yang \\ Wuhan Iron \& Steel Co. Ltd., Wuhan, China \\ Email:hukh@baosteel.com
}

How to cite this paper: Hu, K.H., Zhou, S.Z., Han, R.D., Gao, J. and Yang, Y. (2018) Microstructure Evolution and Simulation in $22 \mathrm{MnB5}$ Steel during Hot Stamping. Journal of Materials Science and Chemical Engineering, 6, 9-14.

https://doi.org/10.4236/msce.2018.68002

Received: July 19, 2018

Accepted: August 5, 2018

Published: August 8, 2018

Copyright $\odot 2018$ by authors and Scientific Research Publishing Inc. This work is licensed under the Creative Commons Attribution International License (CC BY 4.0).

http://creativecommons.org/licenses/by/4.0/

\begin{abstract}
Hot stamping components with $1500 \mathrm{MPa}$ ultra-high strength are obtained by press hardening during hot stamping, and the properties depend on the microstructures. It is very important that the microstructure evolution rule is found out during hot stamping process. To characterize the microstructure evolution during hot stamping, a method combining finite element and experiment is carried out. Samples were heated to $950^{\circ} \mathrm{C}$ and held for 300 second at a induction heating furnace, then taken out from the furnace and stayed in the air at different time $(7 \mathrm{~s}, 11 \mathrm{~s}, 13 \mathrm{~s}, 22 \mathrm{~s})$, respectively, finally the specimens were formed and quenched at a die. Microstructural observation as well as surface hardness profiling of formed specimens was performed. And the numerical simulation to predict the austenite transformation into ferrite, pearlite, bainite, and martensite and the volume fraction of each phase during the hot stamping process was made with ABAQUS software. The results show that the ferrite is observed when the specimen stays in the air for $22 \mathrm{~s}$, and the temperature drops to $325^{\circ} \mathrm{C}$ when the dwell time increases from $7 \mathrm{~s}$ to $22 \mathrm{~s}$. The results of numerical simulation and experimental results are in good agreement. So the method finite element can be used to guide the optimization of hot stamping process parameters.
\end{abstract}

\section{Keywords}

Hot Stamping Process, Simulation, Microstructure Evolution, 22MnB5 Steel

\section{Introduction}

Even though a new generation advanced high strength steels with ultra-high strength and excellent formability are developed. The application of press hardening steel is still increased for the safety parts of body in white, due to the much higher demand for light weight of car body, guaranteeing the driver and 
passenger safety, and lower gas emission [1] [2]. During hot stamping process, the steel sheets are austenitized at temperatures between $900^{\circ} \mathrm{C}$ and $950^{\circ} \mathrm{C}$ and soaked for 4 to 8 minutes to obtain a homogenous austenitic microstructure. Then the heated steel sheets are transferred from the oven to a die with cooling system. The steel sheets are formed and quenched in the cooled die, and complex geometries parts are obtained due to the high formability of the hot material. During quenching process, the austenitic microstructure transforms into a martensitic one. The ultimate tensile strength of the steel sheets is increased to approximately $1500 \mathrm{MPa}$ because of the martensite evolution [3]. So the microstructure evolution during hot stamping process is important.

Nikravesh, et al. [4] simulated the hot stamping process by a deformation dilatometer to investigate the phase transformations. $\mathrm{Wu}$, et al. [5] developed a coupled 3D thermomechanical phase transformation finite element simulation of the hot stamping process. The mechanism of martensitic transformation was investigated by Khan [6]. New models were developed to predict the grain growth during hot stamping process by Zhu, et al. [7]. Nevertheless, the effect of time to stay in the air of the austenitizing steel sheet on the phase transformations has rarely been investigated and unclear.

In this paper, the effect of the time of staying in the air during the samples being transferred on the phase transformation was analyzed, considering the influence of the sample temperature on the diffusion and diffusionless phase transformation. The current work focus on the influence of the different time of staying in the air on subsequent phase transformations. And the volume fraction of each phase during the hot stamping process was numerical simulated with ABAQUS software.

\section{Experimental Methods}

$1.5 \mathrm{~mm}$ sheet of $22 \mathrm{MnB} 5$ press hardening steel with a composition of $\mathrm{Fe}-0.22 \mathrm{C}$ $0.25 \mathrm{Si}-1.20 \mathrm{Mn}-0.20 \mathrm{Cr}-0.002 \mathrm{~B}$ (wt\%) was used in this work. The microstructures of as-reveived steel are $76 \%$ ferrite and $24 \%$ pearlite.

The samples were heated up to $950^{\circ} \mathrm{C}$ for $300 \mathrm{~s}$, then taken out from the furnace and stayed in the air at different time (7 s, 11 s, $13 \mathrm{~s}, 22 \mathrm{~s})$, that is sample transfer time, respectively, finally the specimens were formed and quenched at a die with water cooling system. And this process was simulated by using ABAQUS software. The microstructures were examined by light optical microscope, and the samples were inlayed in epoxy resin, ground and polished into mirror face using 180, 400, 800 and 1200 emery papering, subsequently by 2.5 $\mu \mathrm{m}$ and $1 \mu \mathrm{m}$ polishing agent. The specimens were then etched using a $3 \% \mathrm{Natal}$ solution for microstructure observation. And the volume fraction of every phase with different transfer time was simulated.

\section{Results and Discussion}

\subsection{Effect of Transfer Time on the Microstructure of 22MnB5}

Figure 1 shows the microstructures of the samples after hot stamping process 

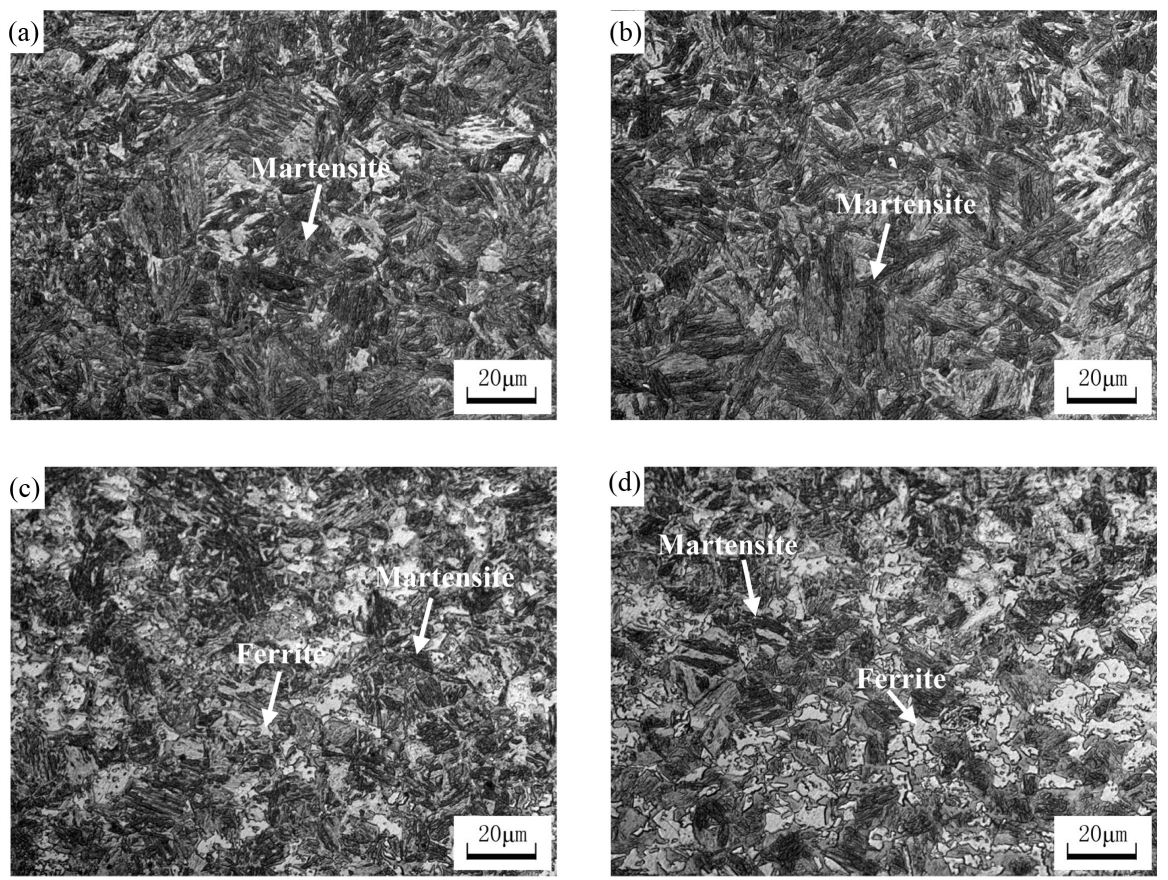

Figure 1. Microstructures obtained after hot stamping process with a transfer time: (a) 7 s, (b) $11 \mathrm{~s},(\mathrm{c}) 13 \mathrm{~s}$, (d) $22 \mathrm{~s}$.

with different transfer time. As shown in Figure 1(a) and Figure 1(b), the specimens after hot stamping process with $7 \mathrm{~s}$ an $11 \mathrm{~s}$ transfer time obtain a fully martensitic microstructure. This is due to the austenitized specimens were still a fully austenitic microstructure before it were formed and quenched, because the temperature drop of the austenitized specimens was relatively small. Such as the temperature of the sample with $7 \mathrm{~s}$ transfer time reduced from $950^{\circ} \mathrm{C}$ to $819^{\circ} \mathrm{C}$, the reduction temperature from $950^{\circ} \mathrm{C}$ to $742^{\circ} \mathrm{C}$ for the sample with $11 \mathrm{~s}$ transfer time. When the heated sample was stayed at air up to $13 \mathrm{~s}$, as shown in Figure 1 (c), based on the effects of temperature on the phase transformation behaviour, a small amount of the prior ferrite was generated. However a considerable amount of ferrite was appeared in the microstructure in Figure 1(d) after hot stamping process. Because the temperature of specimen with $22 \mathrm{~s}$ staying time at air was dropped from $950^{\circ} \mathrm{C}$ to $625^{\circ} \mathrm{C}$, obviously, the heated sample had already entered the two phase region. So the austenitized specimens can not stay time longer than $11 \mathrm{~s}$ from the heating furnace to the die during hot stamping process.

\subsection{Effect of Transfer Time on the Microstructure Based on Simulating}

In the present work, the hot stamping process including forming, quenching, and transfer time was simulated by ABAQUS software. A quarter of die and steel sheet was selected to simulate the hot stamping process, because of the symmetrical die and surroundings environment. Figure 2 shows the finite element model of hot stamping process for a U-shaped part. During the simulating 


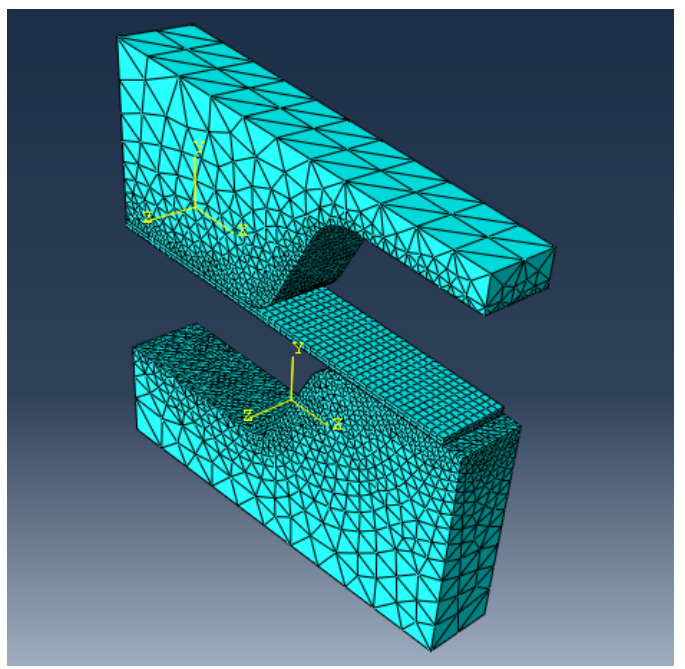

Figure 2. The finite elements model.

process, the material of die is H11, and the relevant parameters are showed in Table 1. The empirical JMAK constitutive relation is applied to calculate the volume fraction of the diffusion phase transformation. The following form of the JMAK relation is given [8]:

$$
F=1-\exp \left(-b \times t^{n}\right)
$$

where $F$ is the volume fraction of phase, $b$ is a constant of the relevant of temperature, phase and grain size, $t$ is current time, $n$ is a constant of phase transformation, $b$ and $n$ can be obtained by the isothermal transformation curve calculation.

The diffusionless phase transformation from austenite into martensite is simulated by using the finite element method, the volume fraction of martensite can be calculated by the relation given [8]:

$$
F_{m}=F_{a} \times\left\{1-\exp \left[-0.011 \times\left(M_{s}-T\right)\right]\right\}
$$

where $F_{m}$ is the volume fraction of martensite, $F_{a}$ is the volume fraction of the remaining austenite when the phase transformation from austenite into matensite is start, $M_{s}$ is the start temperature of martensitic transformation, $T$ is the actual time.

The simulating results show a large amount of ferrite formation when the transfer time is up to $22 \mathrm{~s}$. Figure 3 shows the volume fraction of austenite with the transfer time from $0 \mathrm{~s}$ to $25 \mathrm{~s}$. It is apparent that the volume fraction of austenite reduces when the specimen stays time at air is $22 \mathrm{~s}$ or more, that means the sample into the two-phase region. With this model, we found consistently with the hot stamping process experiment that the effect of transfer time on the microstructure evolution. Figure 4 shows the distribution of martensite with 22 $\mathrm{s}$ transfer time, and it is crystal clear that the volume fraction of martensite decreases with the volume fraction of austenite, which is due to generate the austenite to ferrite transformation when the hot specimen stays at air for a long time. 
Table 1. The relevant parameters of the die for the simulation of hot stamping process.

\begin{tabular}{ccccc}
\hline $\begin{array}{c}\text { Heat transfer } \\
\text { coefficient/ } \\
\mathrm{W} \cdot \mathrm{m}^{-1} \cdot \mathrm{k}^{-1}\end{array}$ & $\begin{array}{c}\text { Specific heat } \\
\text { capacity } / \mathrm{J} \cdot \mathrm{kg}^{-1} \cdot \mathrm{c}^{-1}\end{array}$ & Density $/ \mathrm{kg} \cdot \mathrm{m}^{-3}$ & $\begin{array}{c}\text { Young } \\
\text { modulus/GPa }\end{array}$ & $\begin{array}{c}\text { Poisson's } \\
\text { ratio }\end{array}$ \\
\hline 422 & 526 & 7700 & 210 & 0.3 \\
\hline
\end{tabular}

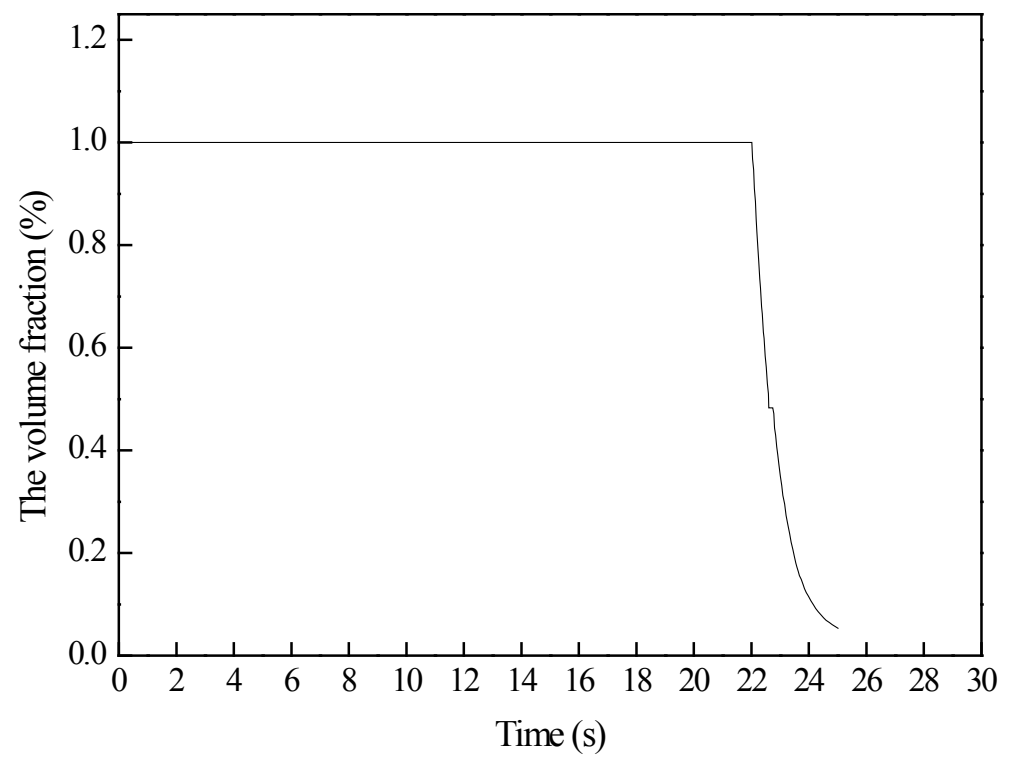

Figure 3. The volume fraction of austenite with different transfer time.

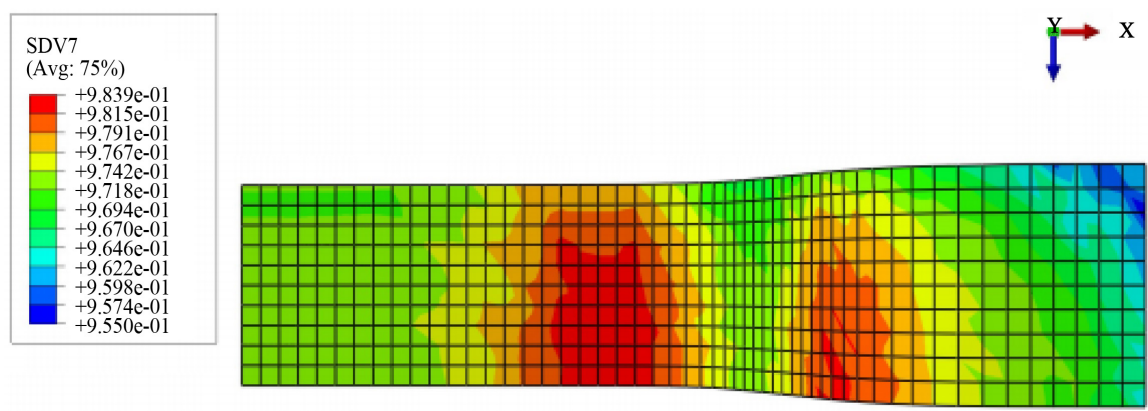

Figure 4. The distribution of martensite with $22 \mathrm{~s}$ transfer time.

\section{Conclusion}

The effect of transfer time on the phase transformation of hot stamping process is significant, the ferrite formation will occur when the transfer time is up to 13 s. and a considerable amount of ferrite was appeared in the microstructure with the transfer time $22 \mathrm{~s}$. The results of numerical simulation and experimental results are in good agreement. So the method finite element can be used to guide the optimization of hot stamping process parameters.

\section{Conflicts of Interest}

The authors declare no conflicts of interest regarding the publication of this paper. 


\section{References}

[1] Karbasian, H. and Tekkaya A.E. (2010) A Review on Hot Stamping. Journal of Materials Processing Technology, 210, 2103-2118. https://doi.org/10.1016/j.jmatprotec.2010.07.019

[2] Xing, Z.W., Bao, J. and Yang, Y.Y. (2009) Numerical Simulation of Hot Stamping of Quenchable Boron Steel. Materials Science and Engineering A, 499, 28-31. https://doi.org/10.1016/j.msea.2007.09.102

[3] Bardelcik, A., Worswick, M.J. and Wells, M.A. (2014) The Influence of Martensite, Bainite and Ferrite on the As-Quenched Constitutive Response of Simultaneously Quenched and Deformed Boron Steel-Experiments and Model. Materials and Design, 55, 509-525. https://doi.org/10.1016/j.matdes.2013.10.014

[4] Nikravesh, M., Naderi, M., Akbari, G.H. and Bleck, W. (2015) Phase Transformations in a Simulated Hot Stamping Process of the Boron Bearing Steel. Materials and Design, 84, 18-24. https://doi.org/10.1016/j.matdes.2015.06.108

[5] Wu, W., Hu, P. and Shen, G. (2015) Thermomechanical-Phase Transformation Simulation of High-Strength Steel in Hot Stamping. Mathematical Problems in Engineering, 2015, Article ID: 982785. https://doi.org/10.1155/2015/982785

[6] Zhu, K., Chen, H., Masse, J.P., Bouaziz, O., et al. (2013) The Effect of Prior Ferrite Formation on Bainite and Martensite Transformation Kinetics in Advanced High-Strength Steels. Acta Materialia, 61, 6025-6036. https://doi.org/10.1016/j.actamat.2013.06.043

[7] Zhu, L.J., Gu, Z.W., Xu, H., et al. (2014) Modeling of Microstructure Evolution in $22 \mathrm{MnB} 5$ Steel during Hot Stamping. Journal of Iron and Steel Research International, 21, 197-201. https://doi.org/10.1016/S1006-706X(14)60030-3

[8] Song, D.L., Gu, J.F. and Yuan, W.Q. (2004) Numerical Simulation on Quenching Process of Large-Sized Plastic Mould Made of Steel 718. Materials for Mechanical Engineering, 28, 22. 